\title{
Fuzzy Inferensi System dengan Tsukamoto pada Penilaian Kepuasan Pelangan di Cafe Pasco Pematangsiantar
}

\author{
Dolli Sari Sinaga ${ }^{1}$, Feby Widya Sari ${ }^{2}$ \\ ${ }^{1,2}$ Mahasiswa Program Studi Sustem Informasi, STIKOM Tunas Bangsa, Pematangsiantar \\ febywidya0200@gmail.com
}

\begin{abstract}
The development of cafe business is increasingly rapid, demanding that the cafe always create innovations and new concepts that are able to attract more consumers. The main key in attracting consumers in addition to innovation and new concepts is the ability of cafes to provide satisfaction to consumers. The purpose of this research is to find out whether customers are satisfied with the service at Pasco Cafe. The method used in this study is the Fuzzy Tsukamoto method. Data was collected by distributing questionnaires / questionnaires to 150 customers at Cafe Pasco. The variables used to assess satisfaction given by the Cafe to consumers are infrastructure $(X)$, price $(Z)$ and service $(Z)$. Where infrastructure has criteria (complete and incomplete [1; 9]), prices have criteria (cheap, normal and expensive [1;6;9]) and services have criteria (satisfied and dissatisfied [2; 9]. example of infrastructure cases has a value of 6 and the price has a value of 5. The results of the assessment of customer satisfaction with service in the Cafe Pasco category satisfied with a value of 5.2462
\end{abstract}

Keywords: Fuzzy, Tsukamoto, Customer Satisfaction, Cafe, Pematangsiantar

\begin{abstract}
Abstrak
Perkembangan bisinis cafe yang semakin pesat, menuntut cafe agar selalu membuat inovasi dan konsep baru yang mampu menarik lebih banyak konsumen. Kunci utama dalam menarik konsumen selain inovasi dan konsep baru adalah kemampuan cafe untuk memberikan kepuasan kepada konsumen. Tujuan dari penelitian untuk mengetahui apakah pelanggan puas terhadap pelayanan di Cafe Pasco Pematangsiantar. Metode yang digunakan pada penelitian ini adalah metode Fuzzy Tsukamoto. Pengambilan data dilakukan dengan penyebaran angket/kuisoner kepada 150 pelanggan di Cafe Pasco pematangsiantar. Variabel yang digunakan untuk penilaian kepuasan yang diberikan pihak Cafe kepada konsumen adalah sarana prasarana (X), harga (Z) dan Pelayanan (Z). Dimana sarana prasarana memiliki kriteria (lengkap dan tidak lengkap [1;9]), harga memiliki kriteria (murah, normal dan mahal $[1 ; 6 ; 9]$ ) dan pelayanan memiliki kriteria (puas dan tidak puas [2;9]. Untuk contoh kasus sarana prasarana memiliki nilai 6 dan harga memiliki nilai 5. Adapun hasil penilaian kepuasan pelanggan terhadap pelayanan di Cafe Pasco kategori puas dengan nilai 5,2462
\end{abstract}

Kata Kunci: Fuzzy, Tsukamoto, Kepuasan Pelanggan, Cafe, Pematangsiantar

\section{Pendahuluan}

Fenomena cafe telah lama mewarnai pola kehidupan masyarakat kita. Biasanya pengunjung akan berlama-lama berada di cafe untuk menikmati secangkir kopi atau menu lain yang disediakan oleh cafe, serta mengobrol. Seiring dengan berkembangnya jaman, masyarakat kota pada saat ini mengalami perubahan gaya hidup (lifestyle). Salah satu manifestasi gaya hidup modern saat ini adalah kebiasaan kelompok masyarakat tertentu yang nongkrong di kafe atau coffee shop. Gaya hidup ini sesuai dengan karakter orang Indonesia yang suka berkumpul. Fenomena maraknya cafe juga terjadi di Pematangsiantar. Kebanyakan dari cafe menyuguhkan menu yang menjadi andalan dari café tersebut. Tidak hanya rasa dari makanan atau minuman yang disediakan saja, namun 
fasilitas seperti wifi dan stop kontak yang menjadi daya tarik pengunjung serta pelayanan yang diberikan oleh pihak café juga menjadi nilai penting agar pengunjung ingin berlamalama dan datang kembali ke café tersebut.

Cafe Pasco merupakan salah satu café yang ada di Kota Pematangsiantar dengan pengunjung kebanyakan adalah usia remaja. Café Pasco menyediakan menu-menu dengan harga terjangkau dikalangan remaja dan juga menyediakan fasilitas seperti, wifi, stop kontak, musholah, kipas angina dan free musik. Kepuasan pengunjung merupakan hal yang tidak boleh diabaikan bagi suatu cafe. Karena kepuasan pengunjung merupakan aspek penting untuk mempertahankan citra cafe tersebut di masyarakat, sehingga cita rasa makanan atau minuman serta pelayanan yang bermutu perlu ditingkatkan. Hal tersebut sangat penting karena mengingat peranan pengunjung yang sangat besar dalam kontribusi pendapatan untuk mendukung eksistensi dari suatu cafe. Banyak ilmu computer yang digunakan dalam melakukan penilaian kepuasan pengunjung, salah satunya adalah fuzzy. Fuzzy memiliki beberapa macam antara lain, fuzzy mamdani, fuzzy sugeno, Fuzzy Tsukamoto dan lain sebagainya. Banyak penelitian terdahulu dalam melakukan penilaian dengan menggunakan metode Fuzzy Tsukamoto seperti [1] dan [2]. Diharapkan penelitian ini dapat menjadi masukan kepada pihak café pasco dalam menjaga cita rasa makanan atau minuman dan meningkatkan kualitas pelayanan mereka.

\section{Metodologi Penelitian}

\subsection{Fuzzy}

Menurut J.-S. R. Jang, et al dalam [3] Fuzzy secara bahasa diartikan sebagai kabur atau samar-samar. Dalam fuzzy dikenal derajat keanggotaan yang memiliki rentang nilai 0 hingga 1. Berbeda dengan himpunan yang memiliki nilai 1 atau 0. Sedangkan logika fuzzy adalah suatu cara yang tepat untuk memetakan suatu ruang input kedalam suatu ruang output, mempunyai nilai kontinyu. Fuzzy dinyatakan dalam derajat dari suatu keanggotaan dan derajat dari kebenaran. Oleh sebab itu sesuatu dapat dikatakan sebagian benar dan sebagian salah pada waktu yang sama.

\subsection{System Inferensi Fuzzy Tsukamoto}

Menurut Kusumadewi dalam [4] Pada Metode Tsukamoto, setiap konsekuen pada aturan yang berbentuk IF-Then harus direpresentasikan dengan suatu himpunan fuzzy dengan fungsi keanggotaan yang monoton. Sebagai hasilnya, output hasil inferensi dari tiap-tiap aturan diberikan secara tegas (crisp) berdasarkan $\alpha$ - predikat (fire strength). Hasil akhirnya diperoleh dengan menggunakan rata-rata terbobot. Berikut gambar inferensi dengan menggunakan Metode Tsukamoto pada gambar 1.

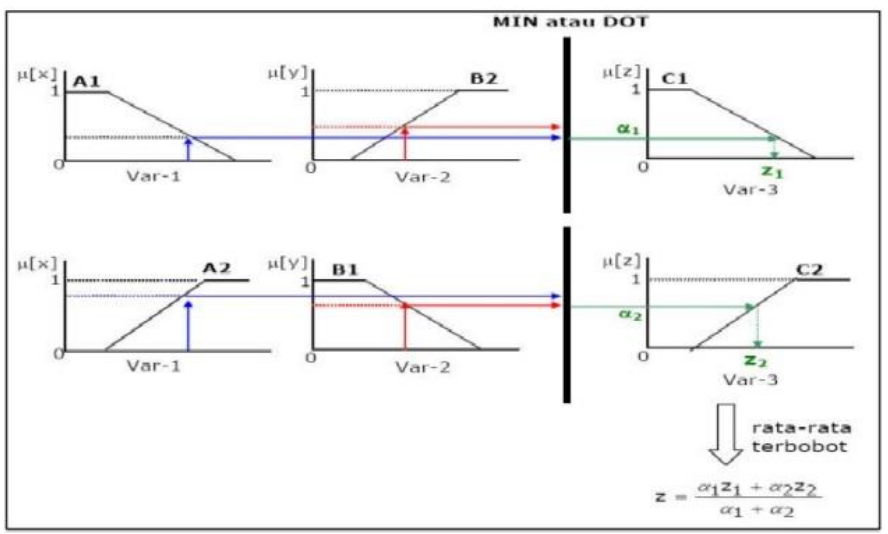

Gambar 1. Fungsi Keanggotaan linear naik 


\section{Hasil dan Pembahasan}

Berikut adalah hasil perhitungan dengan menggunakan metode Tsukamoto dengan pada pada penilaian kepuasan pelangan di cafe pasco pematangsiantar dengan sampel perhitungan terhadap 150 pelanggan di Cafe Pasco pematangsiantar.

$X$ : Sarana Prasarana \{ Lengkap; Tidak Lengkap \}

$Y$ : Harga \{ Murah; Normal; Mahal \}

Z: Pelayanan \{ Puas; Tidak Puas \}

Diketahui :

$X:[1 ; 9]$

$Y:[1 ; 6 ; 9 ;]$

$Z:[2 ; 9]$

Ditanya :

$\mathrm{X}: 6$

$\mathrm{Y}: 5$

$\mathrm{Z}:$ ?

$\mu$ Lengkap $\quad=\frac{\overline{x-a}}{b-a}=\frac{6-1}{9-1}=\frac{5}{8}=0,625$

$\mu$ Tidak Lengkap $=\frac{b-x}{b-a}=\frac{9-a}{9-1}=\frac{a}{a}=0,375$

$\mu$ Mahal $\quad=\frac{x-a}{b-a}=\frac{5-2}{9-2}=\frac{a}{7}=0,612$

$\mu$ Normal $\quad=\frac{\bar{c}-x}{b-a}=\frac{6-5}{9-6}=\frac{1}{a}=0,33$

$\mu$ Murah $\quad=\frac{b-x}{b-a}=\frac{9-5}{9-2}=\frac{4}{7}=0,57$

\section{Rule 1}

$$
\begin{aligned}
\mu \quad & =\mu \mathrm{x}\left(\text { Tidak Lengkap) }{ }^{n} \mu \mathrm{y}(\text { Murah) then } \mathrm{z} \text { tidak puas }\right. \\
& =\min (0,37 ; 0,57) \\
& =0,37
\end{aligned}
$$

Z Tidak Puas $=\frac{x-a}{b-a}$

$$
\begin{array}{ll}
0,37 & =\frac{x-2}{9-2} \\
0,37 & =\frac{x-2}{7} \\
X-2 & =0,37 \times 7 \\
X-2 & =2,25 \\
X & =2,27+2 \\
X & =4,59
\end{array}
$$

\section{Rule 2}

$\mu \quad=\mu \mathrm{x}$ (Tidak Lengkap) $\mathrm{n}^{\mathrm{n}} \mu \mathrm{y}$ (Normal) then $\mathrm{z}$ tidak puas

$=\min (0,37 ; 0,33)$

$=0,33$ 
$\mathrm{Z}$ Tidak Puas $=\frac{x-a}{b-a}$

$$
\begin{array}{ll}
0,33 & =\frac{z-2}{9-2} \\
0,33 & =\frac{x-2}{7} \\
X-2 & =0,33 \times 7 \\
X-2 & =2,31 \\
X & =2,31+2 \\
X & =4,31
\end{array}
$$

\section{Rule 3}

$$
\begin{aligned}
\mu \quad & =\mu \mathrm{x}\left(\text { Tidak Lengkap) }{ }^{n} \mu \mathrm{y}(\text { Mahal }) \text { then } \mathrm{z}\right. \text { tidak puas } \\
& =\min (0,37 ; 0,57) \\
& =0,33
\end{aligned}
$$

$\mathrm{Z}$ Tidak Puas $=\frac{z-a}{b-a}$

$$
\begin{array}{ll}
0,37 & =\frac{\frac{x-2}{9-2}}{9-2} \\
0,37 & =\frac{x-2}{7} \\
X-2 & =0,37 \times 7 \\
X-2 & =2,25 \\
X & =2,25+2 \\
X & =4,29
\end{array}
$$

\section{Rule 4}

$$
\begin{aligned}
\mu \quad & =\mu x(\text { Lengkap }) \cap \mu y(\text { Murah }) \text { then } \mathrm{z} \text { puas } \\
& =\min (0,62 ; 0,57) \\
& =0,57
\end{aligned}
$$

Z Tidak Puas $=\frac{b-x}{b-a}$

$$
\begin{aligned}
0,57 & =\frac{9-x}{9-2} \\
0,57 & =\frac{x-2}{7} \\
9-X & =0,57 \times 7 \\
9-X & =3,99 \\
-X \quad & =3,99-9 \\
-X \quad & =-5,01 \quad=5,01 \\
X \quad &
\end{aligned}
$$

\section{Rule 5}

$$
\begin{aligned}
\mu \quad & =\mu \mathrm{x}\left(\text { Lengkap) }{ }^{\mathrm{n}} \mu \mathrm{y} \text { (Normal) then } \mathrm{z}\right. \text { puas } \\
& =\min (0,62 ; 0,33) \\
& =0,33
\end{aligned}
$$


Z Tidak Puas $=\frac{b-x}{b-a}$

$$
\begin{aligned}
& 0,33=\frac{9-x}{9-2} \\
& 0,33=\frac{x-2}{7} \\
& 9-X=0,33 \times 7 \\
& 9-X=2,31 \\
&-X \quad=2.31-9 \\
&-X \quad=-6,69 \\
& X \quad=6,61
\end{aligned}
$$

\section{Rule 6}

$$
\begin{array}{ll}
\mu \quad=\mu \mathrm{x}(\text { Lengkap }) \cap \mu \mathrm{y}(\text { Mahal }) \text { then } \mathrm{z} \text { puas } \\
=0,42
\end{array}
$$

Z Tidak Puas $=\frac{b-x}{b-a}$

$$
\begin{array}{ll}
0,42 & =\frac{9-x}{9-2} \\
0,42 & =\frac{x-2}{7} \\
9-X & =0,42 \times 7 \\
9-X & =2,94 \\
-X \quad & =2.94-9 \\
-X \quad & =-6,56 \\
X \quad & =6,56
\end{array}
$$

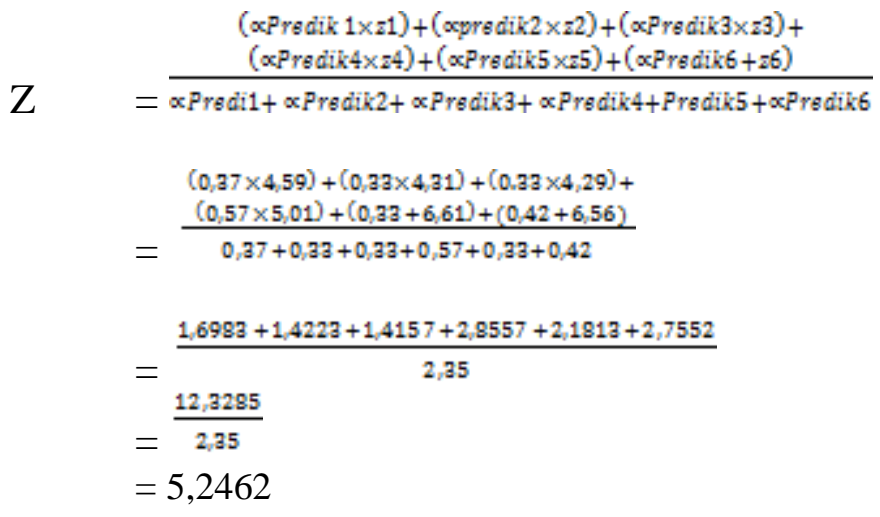

\section{Kesimpulan}

Dari uraian hasil penelitian tentang penilaian kepuasan Pelanggan di Cafe Pasco Pematangsiantar, maka Dapat Disimpulkan Sebagai Berikut:

a) Penilaian kepuasan pelanggan di Cafe Pasco dengan menggunakan metode Tsukamoto dapat diterapkan. Penggunaan Fuzzy logic mempermudah pemecahan masalah tanpa menggunakan metode matematika. Dengan menggunakan metode fuzzy logic, maka penilaian kepuasan pelanggan di Cafe Pasco Pematangsiantar lebih mudah dan cepat.

b) Dengan adanya penilaian kepuasan pelanggan di Cafe Pasco maka dapat melihat hasil kepuasan tingkat pelanggan terhadap konsumen di Cafe Pasco. Adapun hasil 
penilaian kepuasan pelanggan terhadap pelayanan di Cafe Pasco masuk dalam kategori puas dengan nilai 5,2462

\section{Daftar Pustaka}

[1] M. Sholihin, N. Fuad, and N. Khamiliyah, "Sistem Pendukung Keputusan Penentuan Warga Penerima Jamkesmas Dengan Metode Fuzzy Tsukamoto," J. Tek., vol. 5, no. 2, pp. 501-506, 2013.

[2] A. Mulyanto and A. Haris, "Penerapan Metode Fuzzy Tsukamoto Untuk Menentukan Jumlah Jam Overtime Pada Produksi Barang di PT Asahi Best Base Indonesia ( ABBI ) Bekasi Abstrak," J. Inform. SIMANTIK, vol. 1, no. 1, pp. 1-11, 2016.

[3] T. Murti, L. A. Abdillah, and M. Sobri, "Pinjaman Dengan Metode Fuzzy Tsukamoto," Semin. Nas. Inov. dan Tren (SNIT)2015, pp. 252-256, 2015.

[4] W. Kaswidjanti, A. S. Aribowo, C. B. Wicaksono, F. Inference, and F. Inference, "Implementasi Fuzzy Inference System Metode Tsukamoto Pada Pengambilan Keputusan Pemberian,” TELEMATIKA, vol. 10, no. 2, pp. 137-146, 2014. 